\title{
Smallholder farmers livestock production on the face of climate change in Bahir Dar, Zuria District, Northwestern Ethiopia
}

\author{
BIMREW ASMARE`, FENTAHUN MEHERET \\ Department of Animal Production and Technology, College of Agriculture and Environmental Science, Bahir Dar University. P.O Box. 5501, Bahir Dar, \\ Ethiopia."email: limasm2009@gmail.com
}

Manuscript received: 10 October 2018. Revision accepted: 17 November 2018.

\begin{abstract}
Asmare B, Meheret F. 2018. Smallholder farmers livestock production on the face of climate change in Bahir Dar, Zuria District, Northwestern Ethiopia. Biodiversitas 19: 2329-2334. The objective of the study was to assess the livestock production and marketing system in smallholder systems of the area Bahir Dar Zuria district. Three kebeles were selected from Bahir Dar Zuria district based on livestock production experience and accessibility to the road. A total of 90 respondent farmers were used to conduct the assessment, and 4 key informants in each Kebele were used to get additional information. Primary data were collected using a semistructured questionnaire and supplemented with key informants and secondary data sources. Descriptive statistics such as frequency (\%) and mean were employed to present the qualitative variables obtained from the survey. The average land holding in the area was 0.73 ha of total land with 0.53 ha cropland and 0.2 ha private grazing land. With regard to labor allocation for livestock, family labor was involved in $91.18 \%$ of respondents while in the rest hired labor herded, fed, and watered livestock. With regard to water sources, the major source of water for livestock in the households was river $(89 \%)$ while the remaining respondents use dug well for their livestock. The frequency of watering livestock was twice a day (51\%) in the dry season and once a day (44.3\%) in the wet season. Most of respondents (53.65\%) sell their live animals during religious festivities followed by selling during the season of critical feed shortage $(24.45 \%)$. Although smallholder farmers are vulnerable groups to climate change the majority $(42 \%)$ had no information about climate change problem in the study area. The perception of household heads indicated that the livestock holding in the last five years of the family increased in most of the respondents (51\%), followed by decreased condition (33\%) and remained constant for the rest of the respondents $(16 \%)$. Overall, it is important to assist livestock producer in enabling them benefit most from livestock and their products.
\end{abstract}

Keywords: Khatadulis, livestock marketing, livestock production

\section{INTRODUCTION}

Ethiopia is believed to have the largest livestock population in Africa. The livestock sector has been contributing the considerable portion to Ethiopia's economy immensely supporting economic development of the country. Livestock rearing in Ethiopia not only contribute for the economic development but also the livestock products and by-products in the formed meat, milk, hides, egg, cheese, and butter provide the nutritious diet for Ethiopian people (Endalew and Ayalew 2016). Also, it plays an important role in providing export commodities such as live animals, hides, and skins to earn foreign exchanges to the country. Furthermore, livestock is used as draft power for cultivation for land and crop threshing besides their role as a means of transport (CSA 2016). As livestock a "near-cash" capital stock, they serve as insurance in times when crop fails to give yield due to droughts (Ehui et al. 2002). Regardless of the many livestock available, it appears that the country is getting inadequate benefit from this resource, i.e., below the potential both at national and smallholder economy levels mainly due to low productivity.

Among the major setbacks, feed and water shortage, disease and poor veterinary services, lack of appropriate technology, limited attention, poor extension (Shapiro et al. 2015) and problems related to policy and strategy for livestock development can be mentioned as factors that contribute to underutilization of the resource. The driving forces behind these factors include vulnerability contexts like population pressure, agricultural intensification, and degradation of natural resources, shocks through drought and floods and erratic rainfall especially in dry areas. Though knowledge of livestock production is studied earlier, integration of production and marketing of livestock was limited in the study area. Therefore, it is important to conduct an assessment of the livestock production system and marketing systems in the study area. The objective of this paper was to assess livestock production systems of peri-urban areas of district northwestern Ethiopia.

\section{MATERIALS AND METHODS}

\section{Description of the study area}

Bahir Dar Zuria District, Amhara, Ethiopia approximately covers an area of $1,283.6 \mathrm{~km}$ and includes 32 kebeles (smallest administrative division), three of which are partially included in stud because of their accessibility and resources. The district is bounded in the east by south Gonder Zone, in the west by Mecha and Achefer Districts and by Lake Tana, Yelimanadensa District in the north and south, respectively. The 
topographic features of the district indicate that approximately 48 percent can be defined as rolling, 32 percent hill, 13 percent mountainous, 7 percent valleys. The altitude ranges from 1,750 to 2,300 meters above sea level (m.a.s.l). Agriculture is the mainstay of the perop in the study area. It contributes about 100 percent of the population within the area depends on this sector of the economy (CSA 2016). However; it is subsistence, low in production and productivity and backward in its production system and cultural practices involved. In addition to this, the land holding of the farmers, which is the main input of agriculture, is small and highly fragmented as a result of increasing population pressure from time to time (BDZoA 2015).

\section{Procedures and data analysis}

Households possessing at least one farm animal in Bahir Dar zuria district represented the study population. This study was designed to assess the livestock production and marketing status of smallholder farmers in the study area. To undertake this study, the descriptive method was employed. This method was selected because the nature of the problems needs a wide description and investigation. In other words, descriptive research helps to describe and interpret the trend of events that are taking place now and practices that have influenced the current once (Bhattacherjee 2012).

The study was conducted in three Kebele's which were purposely selected based on livestock population and accessibility. From each Kebele, thirty livestock producers were randomly selected and used for the interview. A semistructured questionnaire was used to collect the data on feed storage and feeding system, feed sources, access to feeds, livestock and livestock marketing problems, trends of livestock holding and perceptions on the status of livestock trend

A total of 90 respondent farmers (30 from each Kebele) were used to conduct the assessment and sample was determined using the formula (Yamane 1967):

$$
\mathrm{n}=\frac{N}{1+N\left(e^{2}\right)}
$$

Where $\mathrm{n}$ is sample size computed, $\mathrm{N}$ is the total households in the study area, and e is the level of precision. In addition, to questionnaire interview, 4 key informants in each Kebele were used to get additional information to complement the primary data obtained from the direct interview. Moreover, district and Kebele agricultural officers were included as key informants for the study. Focus group discussions with a group discussion containing 6 participants were held in each Kebele in public areas on key topics of management, nutrition, and watering. The collected data was systematical coded and analyzed with the Statistical Package for Social Sciences (SPSS) (version 20 2011). Descriptive statistics such as frequency $(\%)$ and mean were employed to present the qualitative variables obtained from the survey.

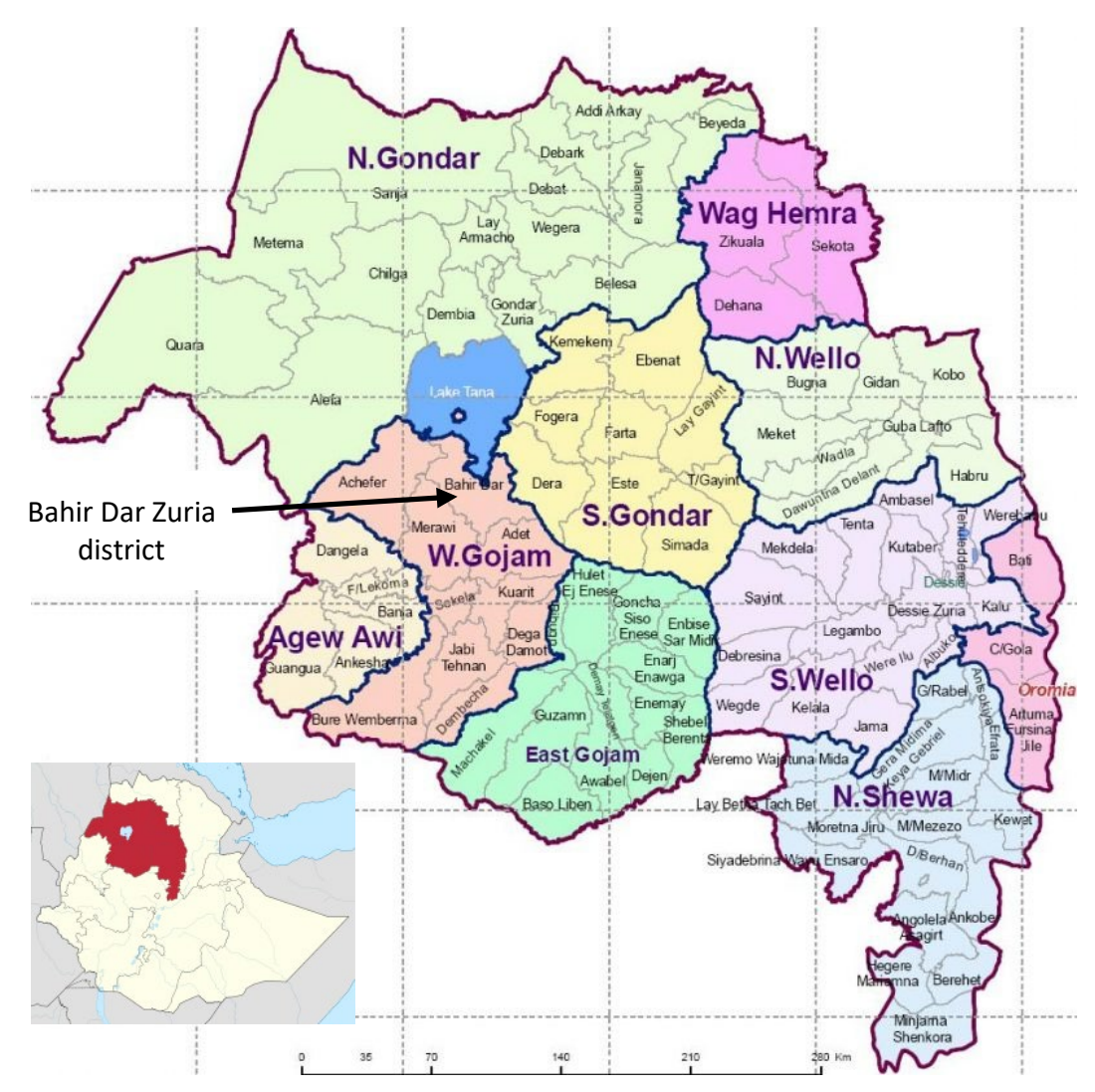

Figure 1. Map of the study area in Bahir Dar Zuria District, Amhara, Ethiopia 


\section{RESULTS AND DISCUSSION}

\section{Household characteristics}

The household characteristics of respondents are shown in Table 1. The overall educational characteristics of respondents in Bahir Dar Zuria districts was found with characteristics that the majority of household heads were literate $(61 \%)$, with the highest number educational was high school completed $(28.50 \%)$, and the rests were illiterate. The report of illiterately class in the three districts is higher than recent reports (Asmare et al. 2016). The overall result of educational characteristics higher than educational characteristics reported by different authors in Ethiopia (Sisay 2006; Bedassa 2012) percentage of the illiterate family members (31.5\%) reported in Burie Zuria district, Ethiopia (Adebabay 2009).

The average age of household heads of respondents was 49.2 years which was higher than Atalay et al. [2015] who reported 43 years for Metekel Zone of Amhara Region and Assefa et al, (2014) who reported an average age 37 years in Oromia Region. The report of illiterate class in the current finding was higher than recent reports in northwestern Ethiopia (Mekuriaw and Asmare 2014; Asmare et al. 2016). The higher literate class has an advantage on the good acceptance of technologies like training, improved agricultural technologies and adopting them for better live improvement. It has been stated that the low level of education of the households can influence on the transfer of agricultural technologies and their participation in development (Mulugeta 2005). The mean family size of respondents is comparable to earlier reports in northwestern Ethiopia (Mekuriaw et al.,2011;G/tsedik and Negash 2016) and comparable to the result of Assefa et al. (2014) for other regions of Ethiopia which was 6-7 per household.

\section{Household income}

The major source of income for all households in the study area was crop (64\%) followed crop and livestock $(26 \%)$ and the remaining $(10 \%)$ were dependent on livestock as the source of income. Moreover, all respondents $(100 \%)$ reported that their additional income is from the sale of Khat (Catha edulis). Respondents also indicated that the income of Khat adulis is obtained from fresh leaves selling to merchants. Like many similar areas of Ethiopia Khat is grown Bahir Dar Zuria district as the area has suitable altitude and environmental variables suitable the plant. In the study area, Khat crop can be harvested around the year, thereby becoming a source of continuous revenue for the farmer. The economically important parts of the plant are its young leaves and tender twigs, which are chewed for their stimulating effect. It is not uncommon to come across many farm ladies selling their plants to willing buyers in the local market throughout the day. Khat chewer population of the area is increasing from time to time similarly with different areas of Ethiopia (Assefa et al. 2014; Kandari et al. 2014).

\section{Land and livestock holding of respondents}

The land and livestock holding of respondents is indicated in Table 2. The area is characterized by a mixed crop-livestock farming system. The average land holding in the area is 0.73 ha of total land with 0.53 ha cropland and 0.2 ha private grazing land. The overall land holding of the study area is lower than 0.98 ha for Debermarkos district (Yayeh et al. 2014). The total landholding of the study area was comparable to the reports of Mekuriaw and Asmare (2014) for Mecha district, northwestern Ethiopia. Generally, the land holding of respondents in the current result is lower than the national average land holding size of 1.6 ha reported by FAO (2008).

The livestock holding of households in TLU (tropical livestock units which represents a mature weight of animals $250 \mathrm{~kg}$ ) was lower than earlier studies in different areas (Solomon 2004; Assefa et al. 2014) which were more than 6 TLUs per household in different parts of the country. This small size TLU in the current finding might be resulted mainly attributed to the shortage of land to grow feed and lack of knowledge in feeding practices of animals. The general observation indicated that mixed croplivestock production system is the dominant farming system in the area livestock being an important component of the mixed farming system and is well integrated with crop production. Livestock species kept by the farmers comprise cattle, sheep, goats, equines, and chicken. Cattle are the dominant species, mainly used for draught power, followed by milk and meat production, income and manure for maintaining soil fertility. The result is in agreement with reports of Belay et al. (2012) in Dandi district, Oromia region, Ethiopia. In the study area, livestock are an integral part of the agricultural systems serving as a source of draught power for land preparation, of meat and milk, of income and savings. The purpose of livestock in the current study area is in line with earlier reports for other areas of the country (Assefa et al. 2014).

Table 1. Household characteristics of respondents $(\mathrm{N}=90)$

\begin{tabular}{ll}
\hline Characteristics of respondents & Percentage \\
\hline Sex of household & \\
Male & $65.25 \%[59]$ \\
Female & $34.75 \%[41]$ \\
Total & $100 \%[90]$ \\
Education level & \\
Illiterate & $39.00 \%[35]$ \\
Elementary school completed & $25.50 \%[23]$ \\
High school completed & $28.50 \%[26]$ \\
College graduate & $7.00 \% \%[6]$ \\
Total & $100 \%[90]$ \\
\hline
\end{tabular}

Table 2. The land and livestock holding characteristics of respondents $(\mathrm{N}=112)$

\begin{tabular}{lc}
\hline Characteristics & Mean \pm SD \\
\hline Total land holding (ha) & $0.73 \pm 0.32$ \\
Crop land holding (ha) & $0.53 \pm 0.15$ \\
Private grazing land (ha) & $0.2 \pm 0.11$ \\
Livestock holding (TLU) & $3.5 \pm 1.71$ \\
\hline
\end{tabular}

Note: $\mathrm{Ha}=$ hectar; TLU=Tropical livestockunit 


\section{Labor division in livestock husbandry and marketing}

In the study area, family labor was involved in $91.18 \%$ of respondents while in the rest livestock are herded, fed, and watered by hired labor. Livestock herding was mostly undertaken by the children aged between 6 to 14 years. Adult males and females also herd cattle during the absence of children. Feed collection, milking, health monitoring, and selling animals were done by both adult man and woman. Other activities such as milk processing, cleaning cattle shed, selling of milk and milk products, cow dung cake making and calf management were performed mostly by females. It is important to make a difference among the types of responsibility that women have over livestock: ownership, control over decision-making, use rights and provision of labour. In most systems, women provide labour for the various tasks related to livestock but may or may not control the process of decision-making, particularly over the disposal of animals and animal products. Similarly, women may be involved in production, but may or may not own the means of production: livestock, land, water, etc. The majority of live animal marketing except chicken was done by males (97\%) while chicken, egg and milk products were sold by females in the household. There are few female respondents $(3 \%)$ who practice selling of cattle, sheep, and equines. Sharing labor for livestock husbandry and marketing of products is in agreement with earlier reports (Assefa et al. 2014).

\section{Livestock feeds and feeding system}

The type of available feed resources in the study area includes natural pasture, crop residue, hay and some indigenous and improved fodder trees like Ficus thoningii tree. Similar result has also been reported by Sisay (2006) in North Gondar. Overall feed resources of the district characterized by grazing natural pasture $(54.2 \%)$ followed by crop residue $(39.1 \%)$ with remaining purchased agro industrial by products. The management of livestock feeding was both partial grazing and home feeding. This home/homestead feeding is an interesting feature of livestock feeding which in turn has enormous advantage to promote fodder development and using cut and carry system which has importance to reduce free grazing. The feed resources in the study area are in agreement with CSA (2015) report that indicated grazing is the major type of feed (about 56.23\%) followed by crops residue that is $35.06 \%$. Hay and by-products were also used as animal feeds that comprise about 7.44 and $1.21 \%$ of the total feeds, respectively.

\section{Water and watering system}

The livestock water source and watering frequency of livestock are indicated in Table 3. Among the major livestock production factors, water availability and quality one of the major limiting inputs as it determines feed availability and quality, health, and overall productivity of farm animals. The result indicated that the major source of water for livestock in the households was the river $(89 \%)$ while the remaining respondents use dug well for their livestock. The frequency of watering in dry and wet season variable in the study area and was mainly twice (51\%) in dry season and once (44.3\%) in the wet season. According to McCornick et al. (2003), water availability can be improved through many ways such as the construction of wells, pumps, canals, boreholes, tanks, cisterns, reservoirs, water yards, dams, and water-harvesting structures. While selecting any given method, there is a need to consider the production system and socioeconomic situation of the farmers.

Sources of water for livestock include drinking water, water contained in feeds and metabolic water (McCornick et al. 2003). Water contained in feeds is highly variable from feed to feed depending on the moisture content, which ranges from as low as $5 \%$ in dry feeds to as high as $90 \%$ or more in wet feeds. For most domestic animals, metabolic water comprises only 5 to $10 \%$ of the water intake, but in the case of sheep, it may rise to $15 \%$ (von Keyserlingk et al. 2016). Drinking water is an essential need, though it is much less than the water required for animal feed production.

\section{Perception of climate change by livestock producers}

Climate change is the major determining factor which governs livestock production and productivity. The poor people living in the least developed countries are typically the most vulnerable to climate change due to the everincreasing weather-related disasters (flooding, drought, storms, and environmental degradation). Ethiopia is in the list of the ten most socially and economically vulnerable countries in the world (IPCC 2007). Smallholder and subsistence farmers, pastoralists, and artisanal fisherfolk are exposed to the complex and localized impacts of climate change, owing to constrained adaptive capacity. Although smallholder farmers are vulnerable groups to climate change the majority $(42 \%)$ had no information about climate change problem in the study area.

The issue of climate change has to be given due consideration to reduce the negative effects on smallholder farmers. One of the ways to mitigate the effects of climate changes is to create awareness about the problem. The increasing occurrence of droughts and floods will affect crop and livestock productivity and will have adverse impacts on food/feed security. This is true particularly in the areas where farmers' consumption mainly depends on agriculture in countries like Ethiopia (IPCC 2007). In Ethiopia, repeated droughts, hunger and the recent floods are among the most climate change serious problems affecting millions of people almost every year.

Table 3. Watering frequency of livestock by respondents $(\mathrm{N}=112)$

\begin{tabular}{lll}
\hline Frequency of watering & $\begin{array}{l}\text { Dry season } \\
\text { percent [N] }\end{array}$ & $\begin{array}{l}\text { Wet season } \\
\text { percent [N] }\end{array}$ \\
\hline & & \\
Once a day & $31.20 \%[28]$ & $44.30 \%[40]$ \\
Twice a day & $51.00 \%[46]$ & $28.70 \%[26]$ \\
More than twice & $18.20 \%[16]$ & $31.00 \%[28]$ \\
Overall & $100 \%[90]$ & $100 \%[90]$
\end{tabular}


Table 4.Perception of respondents on the trends of livestock holding and productivity $(\mathrm{N}=90)$

\begin{tabular}{ll}
\hline Characteristics & Percentage [N] \\
\hline Livestock holding per household head & \\
Increased & $51 \%[46]$ \\
Decreased & $33 \%[30]$ \\
Constant & $16 \%[14]$ \\
Total & $100 \%[90]$ \\
livestock productivity per head & \\
Increased & $38 \%[34]$ \\
Decreased & $44 \%[40]$ \\
Constant & $18 \%[16]$ \\
Total & $100 \%[90]$ \\
\hline
\end{tabular}

Table 5. Livestock marketing options of respondents [ $\mathrm{N}=90]$

\begin{tabular}{ll}
\hline Marketing seasons & Percentage $[\mathbf{N}]$ \\
\hline Religious occasions* & $53.65 \%[48]$ \\
During feed shortage & $24.45 \%[22]$ \\
As demand arises & $21.90 \%[20]$ \\
Total & $100 \%[90]$ \\
\hline
\end{tabular}

Note: *Religious festivity= Easter, Christmas and New Year

\section{Perception of trends of livestock holding and productivity}

The perception of livestock owners on the trends of livestock holding and productivity status is shown in Table 4. The trend of livestock holding of respondent indicated there was variation in terms of holding per household. The finding indicated that for most of the respondents the holding increased $(51 \%)$, while in other respondents there was a decreased $(33 \%)$ state and in some respondents $(16 \%)$ there was a decreased state. Nevertheless, the productivity of animals pe se (per individual) remained low as shown in Table 4. The increment in the population of livestock in the study area is in agreement with the reports of CSA (2015). The reason why respondents increased their animals' population might be to compensate livestock productivity through the large population of livestock. In other cases, constraints like feed shortage, expansion of crop farming, in turn, results from lack of pasture land and climate change effects could be the factors reduce the livestock holdings.

\section{Marketing opportunities}

Livestock marketing determinants of respondents are shown in Table 5. Marketing of live animals is an important trade, especially in countries with a large livestock population. During the discussion in groups of different respondents, it has been pointed out that the several destinations of live animal markets were Bahir Dar, Tiss Abay, Debre Tabor, Estie, and Hamusit. The majority of respondents $(53.65 \%)$ sell their live animals during religious festivities followed by selling during the season of critical feed shortage $(24.45 \%)$. Common avenues for disposal of slaughter cattle are public terminal markets, local auction sale, sale directly on the farm or feedlot, and sale at buying stations. The choice of the most suitable market is not a simple one, and there are no rules for making such a decision. This result is in agreement with earlier reports by different authors (CSA 2015; Moges and Assefa 2017).

In the study area, livestock especially fattening cattle and sheep are purchased and using subjective visual judgment and price negotiation. The livestock marketing in the study area did not use scientific methods of animal marketing such as live animal grading, and price fixation which is the market is in agreement with earlier reports (Alemayehu 2003). Although marketing of livestock and livestock products are the major important activities of the household, most of the livestock producers do not have exact market information. However, the respondents have experience when to fetch high price and producers try to sell livestock during festive and annual occasions.

In conclusion, the study area is characterized by mixed croplivestock production in which land cultivation with oxen was a common practice. Although livestock is important in the livelihood of farmers they are affected by changes in climate which in turn determines production and productivity of animals. The majority of household heads and local livestock experts do have information about the proper market information, and hence, the marketing practice is based on the traditional information on the probability of high prices in festivity and annual holidays. Therefore, it is important to assist livestock producer to get information on how to produce livestock and livestock products at reasonable cost and fetch the high market price.

This study has only highlighted information about the awareness of livestock producers on livestock holding, productivity, and market information and was not detail one which encompassed relatively small size respondents and no modeling of the production system. Hence, it is recommended to have a detailed study on the issue to design appropriate livestock production and marketing in the study area.

\section{REFERENCES}

Adebabay K 2009. Characterization of dairy production systems, marketing and on-farm evaluation of the effect of feed supplementation on milk yield and composition at Bure District, Ethiopia. [Thesis]. Bahir Dar University, Ethiopia.

Alemayehu M. 2003. Country Pasture/Forage Resource Profile, Gov't Ethiopia, Addis Ababa.

Asmare B, Demeke S, Tolemariam T, Tegegne F, Jane W, Barbara R. 2016. Determinants of the Utilization of desho grass (Pennisetum pedicellatum) by farmers in Ethiopia. Tropical Grasslands-Forrajes Tropicales 4: 112-121.

Assefa F, Animut G, Mekasha Y, Urge M. 2014. Assessment of the feeding potential and utilization of Erythrina burana and Casimiroa edulis in Eastern Harerghe zone of Ethiopia. Livestock Res Rural Dev 26(5):82.

BDZoA [Bahir Dar Zuria Office of Agriculture]. 2015: Annual report (unpublished), Bahir Dar district, Bahir Dar, Ethiopia.

Bhattacherjee A. 2012. Social Science Research: Principles, Methods, and Practices. Textbooks Collection. Book 3. USF Open Access Textbooks Collection, Online book.

CSA (Central Statistical Agency). 2015. Federal Democratic Republic of Ethiopia Central Statistical Agency. Agricultural sample survey crop and livestock product utilization bulletin 578.Volume II. Report on Livestock and Livestock Characteristics (Private Peasant Holdings), Addis Ababa, Ethiopia. 
Endalew B, Ayalew Z. 2016. Assessment of the role of livestock in Ethiopia: a review. American-Eurasian J Sci Res 11 (5): 405-410.

FAO. 2008. Ethiopia Country report. Food and Agriculture Organization of the United Nations, Addis Ababa, Ethiopia.

McCornick PG, Kamara AB, Girma T (eds) 2003. Integrated water and land management research and capacity building priorities for Ethiopia. Proceedings of a MoWR/EARO/IWMI/ILRI International Workshop held at ILRI, Addis Ababa, Ethiopia, and 2-4 December 2002. IWMI (International Water Management Institute), Colombo, Sri Lanka, and ILRI (International Livestock Research Institute), Nairobi, Kenya.

Mekuriaw Y, Asmare B. 2014. Assessment of pig production and constraints in Mecha District, Amhara Region, Northwestern Ethiopia. Adv Agric. 2014, ID 329254. DOI: 10.1155/2014/329254.

Mekuriaw Y, Urge M, Animut G. 2011. Role of indigenous bamboo species (Yushania alpina and Oxytenanthera abyssinica) as ruminant feed in northwestern Ethiopia. Livestock Res Rural Dev. 23, Article \#185. http: //www.lrrd.org/lrrd23/9/meku23185.htm. (October 27, 2016)

Moges F, Assefa H. 2017. Chicken production and marketing systems in four selected learning watersheds of Amhara region, Ethiopia. Radix Intl J Res Soc Sci 6(4): 1-14.
Mulugeta A. 2005. Characterization of Dairy Production Systems of Yerer Watershed in Ada Liben Wereda, Oromia Region, Ethiopia. [Thesis]. School of Graduate Studies of Alemaya University, Ethiopia.

Shapiro BI, Gebru G, Desta S, Negassa A, Nigussie K, Aboset G, Mechal H. 2015. Ethiopia Livestock Master Plan. ILRI Project Report, Nairobi, Kenya.

Sisay A. 2006. Livestock Production Systems and Available Feed Resources in Different Agro-ecologies of North Gonder Zone, Ethiopia. [Thesis]. School of Graduate Studies of Alemaya University, Ethiopia.

Solomon B. 2004. Assessment of Livestock Production Systems and Feed Resource Base in Sinana Dinsho District of Bale Highlands, Southeast Oromia. [Thesis]. Haramaya University, Ethiopia.

Yamane, T., 1967. Statistics: An Introductory Analysis. 2nd ed. Harper and Row, New York.

Yayeh Z, Hailemariam M, Belhu K, Asmare B. 2014.Characterization of dairy cattle production systems in Debremarkos district, Amhara Regional State, Ethiopia. Pacesetter J Agric Sci Res 2 (4): 42-51

von Keyserlingk MAG, Phillips CJC, Nielsen BL. 2016. Water and the welfare of farm animals. In: Phillips C. (eds) Nutrition and the Welfare of Farm Animals. Animal Welfare, vol 16. Springer, Cham, Switzerland. 